15

\title{
К вопросу о структурообразовании альбумина
}

\author{
(ㄱ М.Э. Бузоверя, И.В. Шишпор, Ю.П. Щербак
}

Саровский физико-технический институт — филиал Национального исследовательского ядерного университета „МИФИ“, 607186 Саров, Нижегородская обл., Россия

ฯ e-mail: ita.shishpor@yandex.ru

(Поступило в Редакцию 30 ноября 2016 г.)

Проведен микроструктурный анализ дегидратированных на стеклянной подложке образцов сывороточного альбумина человека (САЧ), приготовленных из растворов с разным содержанием белка. Экспериментально показано структурирующее влияние соли $(\mathrm{NaCl})$ на изменение морфологии фаций САЧ. Дано обоснование некоторых структурных эффектов с учетом надмолекулярной организации и полиэлектролитной природы белковой молекулы.

DOI: 10.21883/JTF.2017.09.44922.2118

\section{Введение}

В работах, посвященных исследованиям механизма структурообразования биожидкостей и поискам диагностических алгоритмов на основе морфологического анализа, центральную зону фаций часто называют зоной солевых структур [1-3]. При этом процесс образования фаций САЧ и других биожидкостей рассматривается в основном без учета их специфических особенностей как полимерных и полиэлектролитных систем.

Нами в работах $[4,5]$ на примере сывороточного альбумина частично показан важный вклад полимерности белка в структурообразование фаций. Именно полимерность белков оказывает существенное влияние на неоднородность структуры и свойств фации по толщине, на особенность релаксации внутренних напряжений и характер растрескивания материала. Кроме того, явление микродоменного расслоения с образованием структур определенного морфотипа, характерное для полиэлектролитных белоксодержащих систем, предопределяет не раздельное существование солей и белков, а образование их комплексов как с неорганическими ионами, так и с поверхностно-активными веществами.

В связи с этим пленкообразование из белкового раствора - достаточно сложный физико-химический процесс. В общем виде данный процесс можно представить как взаимодействие частиц, а именно надмолекулярных блоков (комплексов белков с различными углеводами, солями, кислотами и т.д.), сопровождающееся их коалесценцией и деформированием под действием сил различной природы: поверхностного натяжения, капиллярных и электростатических сил, диффузионноосмотических явлений, аутогезии вязкого течения. Поэтому при изучении этого процесса требуется всестороннее рассмотрение.

Чтобы понять и интерпретировать структуру сложных белковых систем, недостаточно ограничиться только изучением их дегидратированных образцов - фаций (пленок). Представляется целесообразным изучить процессы возникновения, развития и распада этих систем с установлением закономерностей эволюции их структуры. В работе [5] было показано, что водно-солевой раствор САЧ является гораздо более структурированной жидкостью по сравнению с водным раствором такой же концентрации. Экспериментально было установлено, что для низких концентраций белка (от 0.2 до 2.0\%) характерно большое многообразие морфологических форм. Также было высказано предположение, что вид и надмолекулярную организацию фаций формирует в основном белковая составляющая раствора, а соль $(\mathrm{NaCl})$ является структурирующей примесью.

С целью определения роли $\mathrm{NaCl}$ в организации структуры фации и выявления первичных структурных элементов сложных надмолекулярных структур (НМС) было проведено исследование фаций сильно разбавленного раствора САЧ. В ходе эксперимента для низких концентраций белка (от 0.002 до $0.2 \%$ ) были получены интересные результаты, на которые мы хотим обратить внимание.

\section{Теоретическая часть}

Прежде чем приступить к интерпретации полученных в ходе эксперимента результатов, необходимо дать некоторые пояснения об особенностях биополимерных систем на основе САЧ.

Известно, что процесс образования пленок из растворов на основе высокомолекулярных соединений (далее полимеров) определяется не только взаимодействием реакционноспособных функциональных групп, но и особенностями структурообразования на надмолекулярном уровне. О влиянии полимерности белков на структурообразование пленок САЧ отмечалось в работах $[4,5]$.

Альбумины относятся к природным полимерам белкам глобулярной природы, макромолекулы которых содержат гидрофобные и гидрофильные группы. Существенным элементом структурообразования является образование неполярного ядра (глобулы) за счет гидрофобных взаимодействий боковых цепей аминокислот. 
Гидрофобные взаимодействия в водных растворах выступают как фактор стабилизации нативных конформаций. Любое изменение конформации влечет за собой изменение функциональных свойств белков.

Конформационные изменения и процессы взаимодействия макромолекул белков, а также характер надмолекулярных структур, образующихся при таком взаимодействии, определяются двумя основными факторами:

- свойствами самих макромолекул, определяемыми химической структурой;

- внешними условиями, которые могут вызвать различного рода взаимодействия при неизменной химической структуре макромолекул. Так, изменение свойств растворителя может привести к ослаблению гидрофобного взаимодействия, поддерживающего компактную глобулярную структуру, которое приводит к разворачиванию глобулы $[6,7]$.

В случае образования пленки на твердой подложке не менее важным является высокая поверхностная активность белковых макромолекул, которая также обусловлена наличием гидрофобных и гидрофильных связей.

Кроме того, аминокислотные цепи белковых молекул содержат кислотные и основные группы, способные к электролитической диссоциации, благодаря чему белки относят к амфотерным полиэлектролитам (полиамфолитам). Наличие в полиэлектролитах групп различной природы определяет возможность возникновения различных видов взаимодействий и повышенную по сравнению с нейтральными полимерами склонность цепей к конформационным переходам при изменении природы растворителя, $\mathrm{pH}$ среды, температуры (от компактных клубков до палочкообразных частиц) [6-8].

Таким образом, особенности молекулярного строения альбумина могут вносить существенный вклад в процессы структурообразования надмолекулярного уровня фаций биожидкостей.

В процессе получения пленок из полимерных систем задача интерпретации структурных эффектов осложняется тем, что адсорбционные взаимодействия пленкообразующего вещества с поверхностью твердых тел сопровождаются формированием неоднородной структуры по толщине пленки. Связано это с неравномерным протеканием физико-химических процессов в объеме и в слоях, граничащих с подложкой и воздухом [9]. Особенно ярко это различие выражено у амфифильных веществ. Адсорбируясь на границах раздела фаз „водавоздух“, „вода-твердое тело“, подобные молекулы лежат полярными группами в воде, а неполярными - во второй фазе. В объеме же водного раствора они глобулизируются, свертываясь так, чтобы наружу (к воде) были обращены преимущественно гидрофильные, а внутрь гидрофобные группы.

Так, при исследовании явления адсорбции на стекле яичного альбумина было выявлено [10], что на границе со стеклом адсорбционный слой находится в более конденсированном состоянии, чем на границе с воздухом. Механизм образования межфазных адсорбционных слоев глобулярных белков представлен следующим образом: вначале на границе раздела фаз образуется монослой из белка с гидрофобными участками, обращенными к гидрофобной поверхности, а гидрофильными - к воде. Следующие молекулы подходят к поверхности раздела благодаря давлению адсорбционного слоя и имеют тенденцию вытеснять с поверхности менее поверхностноактивные сегменты молекул, связанные в монослое силами когезии, вследствие чего сегменты молекул адсорбционного слоя образуют свободные петли или складки. Это приводит к увеличению числа полярных областей молекул на границе раздела фаз. В результате увеличивается гидрофильность слоя, обращенного к воде, что в свою очередь приводит к образованию толстых структурированных слоев.

Склонность белков к образованию надмолекулярных структур с высоким уровнем межмолекулярного взаимодействия сказывается на особенностях адсорбции белков на твердой подложке. Для белков, как показано в работе [11], предпочтителен агрегативный механизм адсорбции, т.е. предпочтительная адсорбция на подложку агрегатов перед отдельными молекулами. При агрегативном механизме адсорбции с изменением концентрации растворов полимеров происходят непрерывные изменения формы макромолекул, а также степени агрегации и характера структур. Фактически при каждом разбавлении мы имеем новую структуру сорбируемых частиц.

В свете вышеизложенного проведем структурный анализ фаций САЧ, полученных из водно-солевых растворов САЧ разных концентраций.

\section{Экспериментальная часть}

\section{Материалы и пробоподготовка}

Исходный 10\%-ный водный раствор САЧ (ФГУП НПО „Микроген“ МЗ РФ, Нижний Новгород) разводили 0.9\%-ным раствором хлорида натрия до заданных концентраций. Приготовление образцов осуществлялось методом открытой дегидратации на твердой подложке [5]. На чистое предметное стекло наносили каплю раствора объемом 10-20 1 . Затем высушивали при комнатной температуре от 22 до $25^{\circ} \mathrm{C}$ и относительной влажности воздуха от 30 до 50\%. Температура и влажность контролировались с помощью лабораторного термогигрометра ИВТМ-7.

В результате дегидратации водно-солевого белкового раствора образуется фация/пленка, подготовленная для дальнейшего исследования методами оптической микроскопии. Чтобы убедиться в воспроизводимости полученных результатов, каждый раствор (и образцы из него) приготавливался многократно. 


\section{Микроструктурные исследования}

Исследования микроструктуры проводили на аппаратно-программном комплексе „Морфо“ на базе оптического микроскопа „ПОЛАМ 211P“.

\section{Результаты и обсуждение}

Как было показано [5], изменение концентрации белка в водно-солевом растворе позволяет выявлять разные стадии агрегации и специфические структурные эффекты, сопровождающие процесс пленкообразования из белкового раствора. Кроме того, с понижением содержания белка (ниже 10\%) наблюдаемая структура становится контрастной, а в интервале концентраций от 1 до $0.2 \%$ существенно меняется тип фаций. По-видимому, увеличение содержания $\mathrm{NaCl}$ усиливает влияние на состояние растворителя/воды: тем самым вызывает структурные перестройки альбумина, способствуя разворачиванию цепей. Для подтверждения этого экспериментального результата представлялось целесообразным рассмотреть влияние качества растворителя на надмолекулярную организацию фаций в диапазоне концентраций водносолевого раствора САЧ от 0.2 до $0.002 \%$.

Рассмотрим изменение содержания соли в растворе при разных разведениях САЧ в диапазоне концентраций от 0.2 до $0.002 \%$. В исходном $10 \%$-ном водном растворе САЧ растворителем является вода. Разведение осуществлялось при помощи $0.9 \%$-ного раствора $\mathrm{NaCl}$, в связи с чем в растворе увеличивалось содержание соли. Соль, меняя состояние воды как исходного растворителя, влияет на конформацию белка [10]. Поэтому считаем, что рассматривать зависимость изменения морфологии фаций от изменения только общего количества белка недостаточно. Исходя из этого была исследована зависимость типа фаций от соотношения „соль-белок“.

На рис. 1 представлен график расчетных данных массовой доли $\mathrm{NaCl}$, приходящейся на долю растворителя. На графике видно, что изменение содержания соли с увеличением содержания белка в растворе САЧ имеет нелинейный характер. Аппроксимирующая кривая соответствует полиномиальному типу (рис. 1).

Представлялось целесообразным рассмотреть изменение относительного соотношения „соль/белок“ в растворе при изменении концентрации САЧ (рис. 2). Для этого был введен условный коэффициент $K_{\mathrm{NaCl}}$ /albumin (далее „коэффициент соли“), который представляет собой отношение реального содержания $\mathrm{NaCl}(\mathrm{g} / \mathrm{ml})$, приходящейся на долю растворителя, к содержанию альбумина $(\mathrm{g} / \mathrm{ml})$.

На графике наблюдается резкое падение значения коэффициента в пределах увеличения концентрации САЧ от 0.002 до $0.02 \%$. При увеличении концентрации САЧ свыше $0.02 \%$ кривая становится более пологой; а с концентрации белка от 0.6 до $10 \%$ САЧ значение коэффициента практически не меняется. В логарифмическом масштабе зависимость коэффициента соли от общей

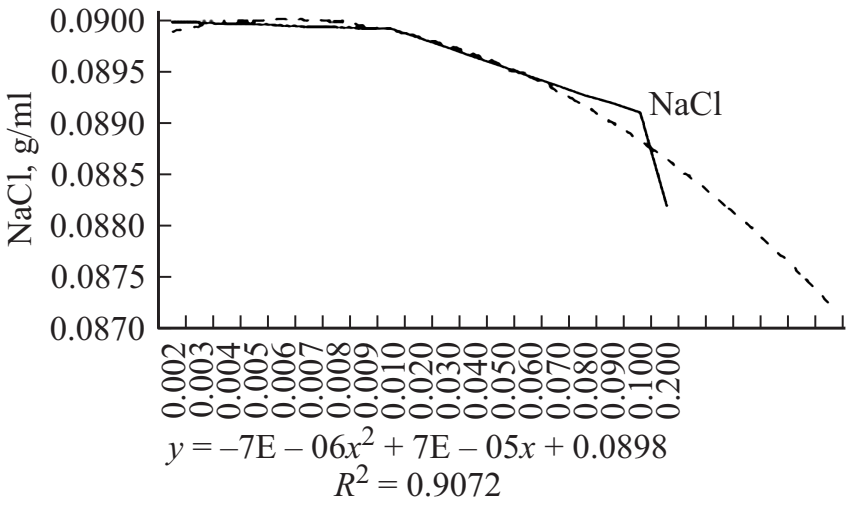

Albumen concentration, $\%$

Рис. 1. Изменение содержания $\mathrm{NaCl}$ в водно-солевых раствоpax CAЧ.

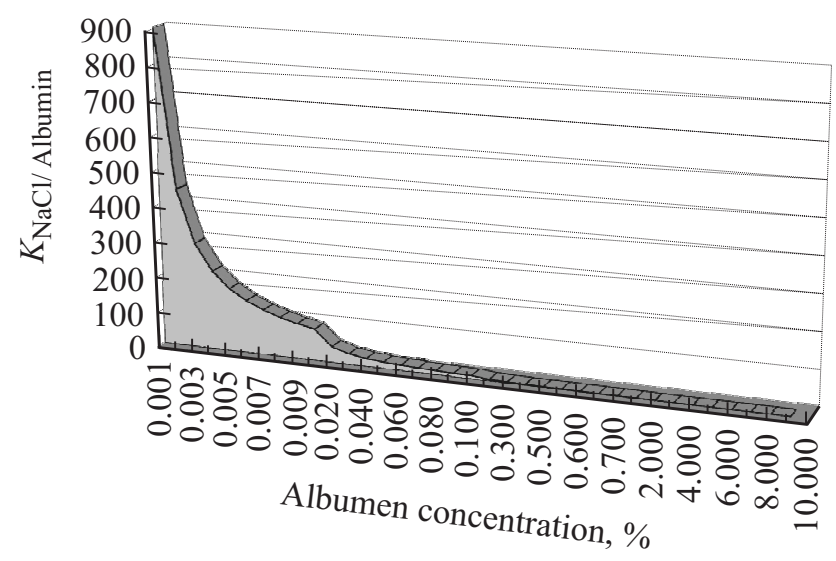

Рис. 2. Изменение значений коэффициента $K_{\mathrm{NaCl} / \text { albumin }}$ при изменении концентрации САЧ.

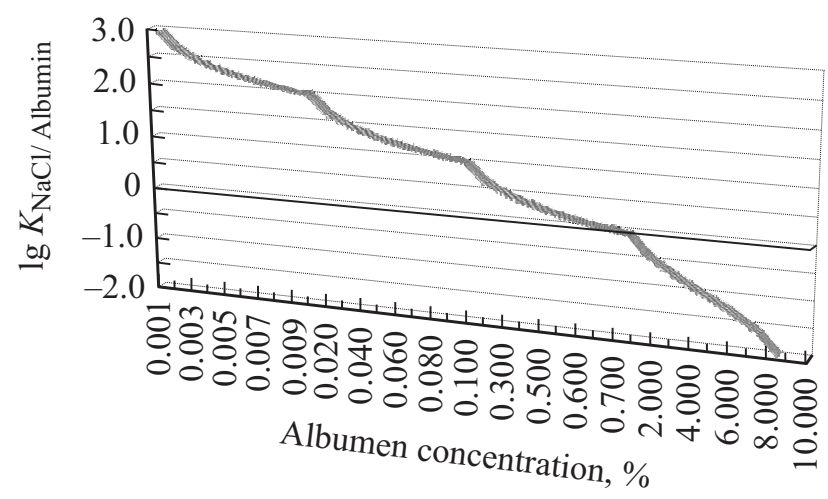

Рис. 3. Изменение значений коэффициента $K_{\mathrm{NaCl} / \text { albumin }}$ при изменении концентрации САЧ в логарифмическом масштабе.

концентрации белка в исследованном интервале концентраций (от 0.002 до $0.9 \%$ САЧ) более показательна (рис. 3).

Видно, что при увеличении содержания белка в растворе коэффициент падает ступенчато. Точки перегиба соответствуют концентрациям 0.02, 0.1, 1.0\%. Как пока- 
зал дальнейший анализ структур фаций, этим концентрациям соответствуют изменения морфологического типа фаций.

\section{Сопоставление с результатами микроструктурного анализа}

На рис. 4 представлены характерные структуры фаций для интервала концентраций САЧ от 0.002 до $0.2 \%$.

Сравнительный анализ фотографий образцов показал, что для низких концентраций альбумина (0.002\%) наблюдается наибольшее разнообразие морфологических форм надмолекулярных структур, закладываемых в растворе. На рис. 4 видно, что даже при таких низких концентрациях водно-белковый раствор САЧ хорошо структурирован. Снижение концентрации САЧ от 0.2 до $0.002 \%$ принципиально не изменяет общий тип фации. Для этих концентраций характерно наличие кольцевых структур с центром структурообразования (домен), дискретных многослойных образований разного размера и формы, надмолекулярных структур сложных форм. Меняется качество основных структурных элементов. Отличительной особенностью фаций низких концентраций является: рыхлость и дефектность структур, вырождение доменов вплоть до их исчезновения и большее количество пластинчатых форм. Особенно при этих концентрациях ярко выражено „огрубление“ рельефа слоевых структур и границ раздела крупных структурных образований в переходных зонах фации (рис. 5,a). Хорошо просматривается многослойность дискретных структур пластинчатого типа (рис. $5, b$ ).

На рис. 5, а представлен фрагмент краевой зоны фации с содержанием белка $0.002 \%$. Видно, что краевая зона
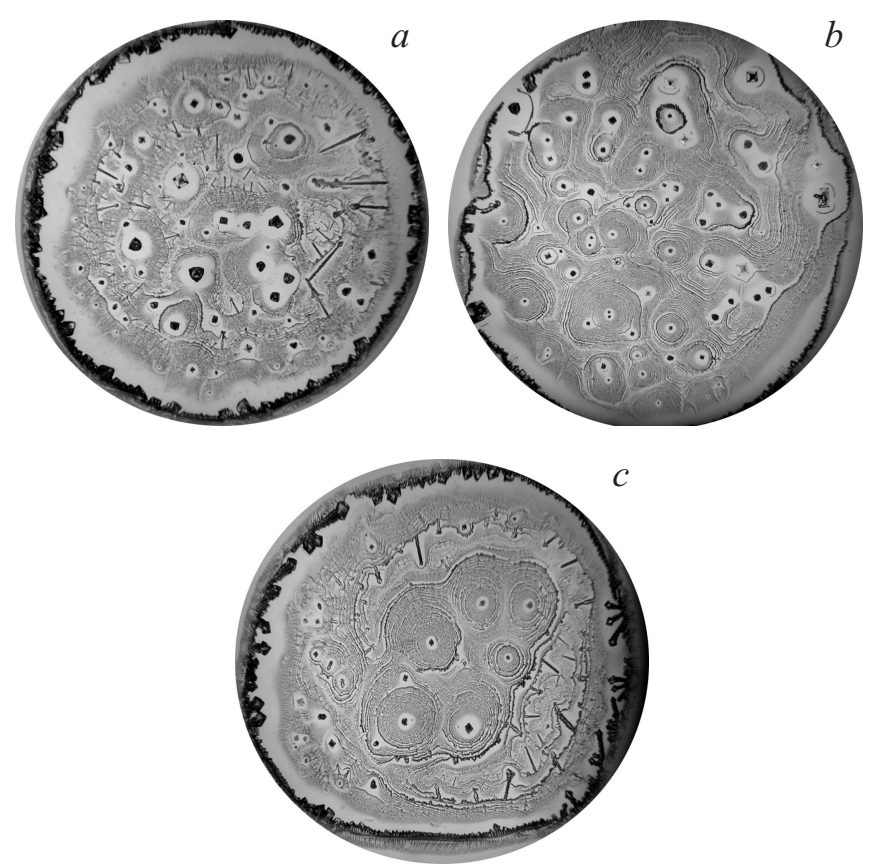

Рис. 4. Микроструктура фаций САЧ с разным содержанием белка: $a-0.002, b-0.02, c-0.2 \%$.

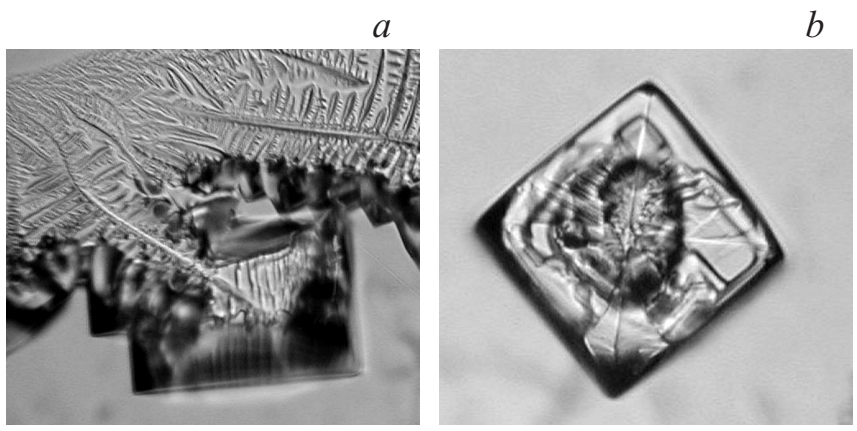

Рис. 5. Микроструктура фаций САЧ с содержанием белка $0.002 \%: a-$ фрагмент краевой зоны, $b-$ пластинчатый структурный элемент центральной зоны. Увеличение 400.

хорошо структурирована, что свидетельствует о выраженных процессах ассоциации белковых молекул уже при таких низких концентрациях белка. Пластинчатые структуры растут на сложном надмолекулярном образовании разветвленной формы из вытянутых структурных элементов, которые, в свою очередь, лежат на подложке, т. е. в адсорбционном слое. Рост полимерных структур из сильно разбавленного раствора, когда структуры с вытянутыми цепями являются подложкой для кристаллов со сложенными цепями, известен для многих полимерных систем и рассматривается в работе [10].

Границы раздела частиц обычно являются местами преимущественного выделения второй фазы и сегрегации примеси. Поэтому одной из причин появления пластинчатых форм может быть захват ионов солей наружными гидрофильными слоями и их совместная кристаллизация. Кроме того, повышенное содержание соли в области контакта наружных слоев структур со средой может способствовать переходу глобулярных форм, характерных для САЧ, в более жесткие развернутые формы, что также может приводить к образованию надмолекулярных структур пластинчатых форм.

Обращает внимание утолщение структур на межфазных границах „структура-среда“. Особенностью белковых систем является гидрофильно-гидрофобная природа макромолекулы. Поэтому на границе раздела фаз с твердой подложкой образуется слой белка с гидрофобными участками, обращенными к подложке и гидрофильными к воде [6]. Такой характер поведения белковых молекул на границах раздела может служить одним из объяснений наличия протяженного переходного слоя между краевой и центральной зоной фаций (рис. 4) и причин образования утолщения наружных слоев отдельных структурных элементов (рис. 5).

Каждой концентрации САЧ соответствует разное соотношение соли и белка в растворе и разные структуры сорбируемых частиц. Было замечено, что при концентрации $0.1 \%$ САЧ происходит распад структур центральной зоны фаций: вырождение доменов, исчезновение слоевых структур. Этой концентрации на графике зависимости коэффициента соли от концентрации 
белка соответствует „точка перегиба“ (рис. 3). При концентрации $0.2 \%$ САЧ (рис. $6, a$ ) структура центральной зоны восстанавливается и до концентрации $1.0 \%$ меняется незначительно. При концентрации $1.0 \%$ САЧ (рис. $6, b$ ) происходит перестройка структур доменного типа: центральная зона фации асимметрична, домены отсутствуют, появляются дендритные структуры, которые в фациях $2.0 \%$-ного водно-солевого раствора САЧ являются основными структурами центральной зоны (рис. 6,c).

Таким образом, так называемая „солевая зона“ в виде дендритов появляется при концентрациях выше 1.0\% САЧ, где „коэффициент соли“ практически не меняется (рис. 3).

Интересную информацию можно получить из анализа структур распада. В фациях низких концентраций на оптическом уровне хорошо визуализируется ступенчатый механизм распада надмолекулярных структур, который подтверждает многослойную организацию структур САЧ. На рис. 7 представлены фрагменты структуры фации $0.02 \%$-ного САЧ. Краевая зона фаций имеет неравномерную структуру разной степени организованности. Можно наблюдать как плотный, структурированный (рис. 7, $a$ ), так и рыхлый слой (рис. 7,b).

При образовании фации одновременно могут происходить как процессы отверждения, так и растворения уже образованной твердой фазы при взаимодействии еe с раствором. Эти процессы фиксируются в фации в виде определенных структур. К примеру, на участке с рыхлой структурой (рис. 7,b) наблюдается распад агрегата сложных форм с освобождением фрагментов структурированного наружного слоя и его сносом из
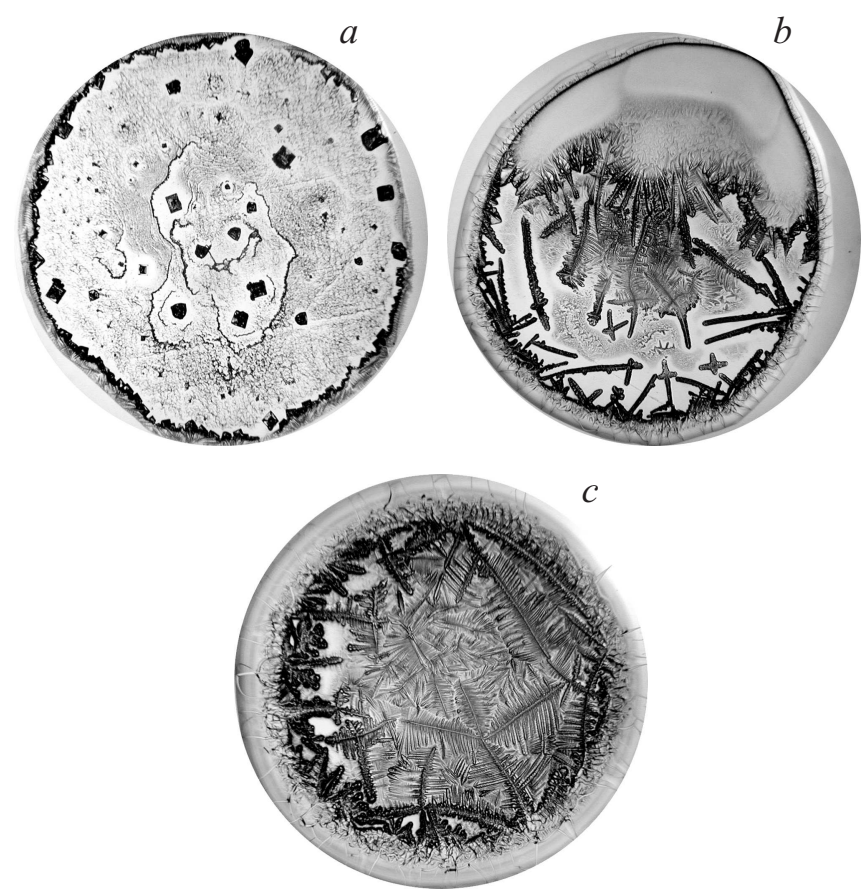

Рис. 6. Микроструктура фаций САЧ с содержанием белка: $a-0.2, b-1.0, c-2.0 \%$.
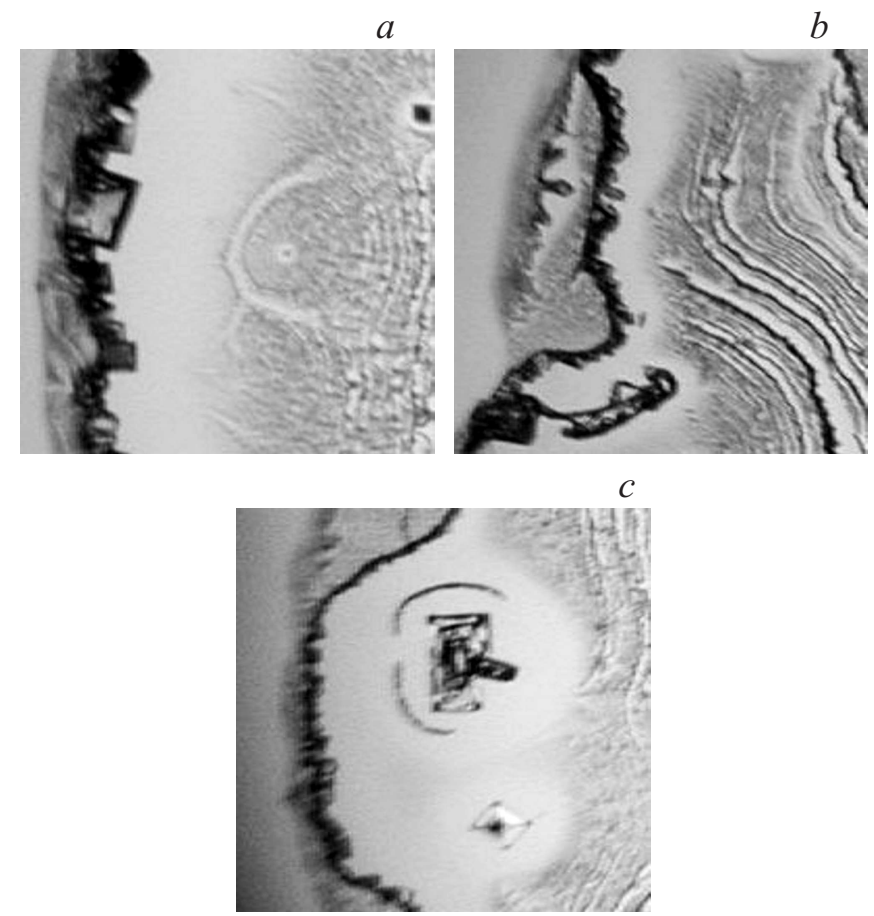

Рис. 7. Фрагменты фации $0.02 \%: a-$ краевая зона с плотной упаковкой структурных элементов, $b-$ область краевой зоны с рыхлой упаковкой, $c$ - распад ассоциата в центральной зоне той же фации.

краевой зоны, с одновременным отделением группы мелких глобул (рис. 7,c).

Таким образом, экспериментальные результаты показывают, что основным пленкообразующим материалом фаций, полученных из водно-солевого раствора САЧ в пределах концентраций от 0.002 до $2.0 \%$, является белок, который может менять свою конформацию (от глобулярной до ламинарной) и образовывать надмолекулярные структуры разных размеров и формы, вплоть до пластинчатых кристаллоподобных.

\section{Заключение}

В рамках небольшого объема настоящей работы описаны лишь некоторые структурные эффекты, наблюдаемые на оптическом уровне в такой сложной системе, как белковый раствор. Нам хотелось на этих примерах продемонстрировать эффективность подхода, основанного на учете особенностей надмолекулярной и полиэлектролитной природе белковых систем.

Простой в экспериментальной реализации метод предоставляет большое количество информации о структурах высшего надмолекулярного уровня. Показано, что простым методом оптической микроскопии в белковых системах можно наблюдать и изучать сложнейшие по своей природе надмолекулярные эффекты, сопровождающие процессы дегидратации, растворения, течения, растрескивания. 


\section{Список литературы}

[1] Тарасевич Ю.Ю., Аюпова А.К. // ЖТФ. 2003. Т. 73. Вып. 5. C. 13-18.

[2] Кистович А.В., Чашечкин Ю.Д., Шабалин В.В. // 2010. Т. 80. Вып. 4. С. 41-46.

[3] Шабалин В.Н., Шатохина С.Н. Морфология биологических жидкостей человека. М.: Хризостом, 2001. 304 с.

[4] Бузоверя М.Э., Шишпор И.В., Потехина Ю.П., Щербак Ю.П. // ЖТФ. 2012. Т. 82. Вып. 7. С. 123-128.

[5] Бузоверя М.Э., Шишпор И.В., Щербак Ю.П. // ЖТФ. 2012. Т. 82. Вып. 9. С. 87-94.

[6] Измайлова В.Н., Ребиндер П.А. Структурообразование в белковых системах. М.: Наука. 1974. 268 с.

[7] Современные проблемы биофизики / Под ред. Г.М. Франка, А.Г. Пасынского. М.: ИЛ, 1961. Т. 1.346 с.

[8] Слесарев В.И. Химия: Основы химии живого. Учебник для вузов. СПб.: Химиздат, 2001. 784 с.

[9] Зубов П.И. Структура и свойства полимерных покрытий. М.: Химия, 1982. $256 \mathrm{c.}$

[10] Вундерлих Б. Физика макромолекул. М.: Мир, 1979. Т. 2. $560 \mathrm{c}$.

[11] Липатов Ю.С. Коллоидная химия полимеров. Киев: Наукова думка, 1984. 344 с. 